\title{
Correlation of Self-Reported Breathlessness with Post Exercise Dyspnea in Obesity
}

\author{
Michael Agustin ${ }^{1,2}$, Hong Chang ${ }^{3}$, John Unterborn'1, Augustine Andoh-Duku1 \\ ${ }^{1}$ Department of Pulmonary and Critical Care Medicine, St. Elizabeth Medical Center, Tufts University, Boston, \\ MA, USA \\ ${ }^{2}$ Department of Pulmonary and Critical Care, Guam Regional Medical City, Dededo, GU, USA \\ ${ }^{3}$ Clinical and Translational Science Institute, Tufts University, Boston, MA, USA \\ Email: magustinmd@gmail.com
}

How to cite this paper: Agustin, M., Chang, H., Unterborn, J. and Andoh-Duku, A. (2017) Correlation of Self-Reported Breathlessness with Post Exercise Dyspnea in Obesity. Open Journal of Respiratory Diseases, 7, 141-149.

https://doi.org/10.4236/ojrd.2017.74015

Received: October 14, 2017

Accepted: November 21, 2017

Published: November 24, 2017

Copyright $\odot 2017$ by authors and Scientific Research Publishing Inc. This work is licensed under the Creative Commons Attribution International License (CC BY 4.0).

http://creativecommons.org/licenses/by/4.0/

\section{Open Access}

\begin{abstract}
Background: Dyspnea in obesity is common and dyspnea questionnaires are mostly validated for chronic respiratory diseases. The study aims to assess how modified Medical Research Council (mMRC) dyspnea scale correlates with post exercise dyspnea Borg scale in 6-minute walk test of the obese population. Methods: We performed a retrospective observational study on 342 obese patients with 6 MWT tests from February 2008 to November 2014 at a single tertiary hospital. Linear regression analysis was used to assess the relationship between mMRC and Borg dyspnea score. Fractional polynomial regression was used to analyze the relationship of mMRC and Borg scores with BMI. Results: MMRC dyspnea score was a strong predictor of post exercise dyspnea Borg score in the obese population in a univariate regression model (coefficient $=0.764, p \leq 0.001$ ). When adjusted to age, BMI, 6 MWT distance and PFT parameters in a multivariate regression model, the relationship remained statistically significant (coefficient $=0.587, p \leq 0.001$ ). The relationship was stronger in obese group with no airflow obstruction. Conclusion: In obese population, pre-exercise mMRC dyspnea score correlates significantly with post exercise dyspnea Borg score regardless of airflow obstruction. This is the first validity study regarding mMRC scale in assessing dyspnea in the obese population.
\end{abstract}

\section{Keywords}

Obesity, Dyspnea, Dyspnea Questionnaire, mMRC, Validity Study

\section{Introduction}

Based on epidemiological studies, more than one-third of adults in the United 
States are obese [1]. Obese people are at increased risk of respiratory complains and bronchodilator use despite the lack of objective evidence of respiratory illness [2] [3]. Exertional dyspnea is a common disabling symptom in obesity, but the mechanisms of this remains unclear [4]. Reduced expiratory reserve volume (ERV), functional residual capacity (FRC) and total lung capacity (TLC) are most frequent observed in the obese pulmonary function tests (PFTs) [2]. These are generally related mechanical effect of adipose tissue in chest wall, which reduces total respiratory compliance [2] [4] [5]. Paradoxically, increase in weight has little effect on airway caliber [6]. Cardiopulmonary exercise test in the obese population also showed increased oxygen consumption, increased $\mathrm{CO}_{2}$ production, and impaired ventilatory mechanics [5] [7]. Overall, obese patients end up having multiple tests to determine the pulmonary and cardiovascular component of their breathlessness.

Clinical questionnaires such as baseline dyspnea index (BDI) and modified Medical Research Council dyspnea scale (mMRC) provide subjective ratings of dyspnea although these have been largely used in the assessment of patients with chronic respiratory disease [8]. To our knowledge, only one pilot study has attempted to investigate the potential use of dyspnea questionnaire in the obese population [9]. There is no study that validated the use of any pre-exercise dyspnea scale in the obese population.

The Modified Medical Research Council (mMRC) dyspnea scale does not quantify breathlessness itself. Other tools such as the Borg dyspnea scale is used for quantitative assessment [10]. The 6 MWT has shown good reproducibility and could be used as a fitness indicator in clinical studies in the obese population [11] [12]. Establishing a correlation between qualitative pre-exercise score (mMRC scale) and quantitative post exercise score (Borg scale) would validate the use of dyspnea questionnaire in the assessment of obese breathlessness. The primary objective of the study is to assess how baseline breathlessness measured by mMRC scale correlates with post exercise dyspnea measured by Borg score in a 6-minute walk test. We also aim to individually analyze mMRC and Borg dyspnea scores on different lung function parameters, airflow rates and body mass index (BMI).

\section{Methods}

MMRC dyspnea scale, 6 MWT and Borg dyspnea scale.

The modified Medical Research Council (mMRC) scale is a five-level rating scale based on the patient's perception of dyspnea in daily activities (Table 1). Respiratory disability ranges from none (Grade 0 ) to almost complete incapacity (Grade 4). A score can be obtained quickly which makes it very convenient in an office setting. The mMRC dyspnea scale has been validated for patients with COPD [8] [13] [14].

The 6 minute walk test ( $6 \mathrm{MWT}$ ) is a simple test that measures the distance that a patient can quickly walk on a flat surface in a period of 6 minutes [15]. It evaluates the global and integrated response of systems involved during exercise. 
Table 1. Modified Medical Research Council (MMRC) dyspnea scale [8].

$\begin{gathered}\text { Grade of } \\ \text { dyspnea }\end{gathered}$
Not troubled by breathlessness except on strenuous exercise
1
2
Shortness of breath when hurrying on the level or walking up a slight hill
or has to stop for breath when walking at own pace on the level
4

However, the 6 MWT only assess the submaximal level of functional capacity since subjects choose their own intensity of exercise. The test could be interrupted if the subject opts to take a rest. This 6 MWT reflects the the daily functional exercises as most activities of daily living are performed at submaximal exertion [15]. Patients are asked to rate their baseline dyspnea using Borg dyspneascale (Table 2). The Borg scale is based on the modified CR 10 categorical scale with scores form 0 to 10 , where 0 (as a measure of dyspnea) corresponds to sensation of normal breathing with no dyspnea and 10 corresponds to subject's maximum possible sensation of dyspnea [16]. The same scale was used to assess post exercise dyspnea in each 6 MWT.

\section{Study Design and Measurement}

We performed a retrospective observational study on patients with 6-minute walk tests from February 2008 to November 2014 at a single tertiary hospital. There were 342 obese patients with 6 MWT; 263 of which have complete pulmonary function test (PFT).There were 6 patients with incomplete diffusion capacity measurements. The study includes patients referred for $6 \mathrm{MWT}$ with body mass index (BMI) $\geq 30 \mathrm{~kg} / \mathrm{m}^{2}$ and history of non-specific dyspnea in the presence or absence of airway obstruction. Subjects with known restrictive lung disease and pulmonary fibrosis were excluded. The study was approved by the institutional Review Board of the St. Elizabeth Medical Center and patient consent was waived.

Patient demographics (age and BMI) were systematically recorded. All patients with 6 MWT have either spirometry or full PFT prior to the test. Measurements of Forced Expiratory Volume in 1 second (FEV1), Forced Vital Capacity (FVC,) FEV1/FVC ratio, Total Lung Capacity (TLC), Functional Residual Capacity (FRC), Expiratory Reserved Volume (ERV) and Diffusion Capacity of Carbon Monoxide (DLCO) were obtained. The $6 \mathrm{MWT}$ was performed according to American Thoracic Society (ATS) guidelines [15]. Subjects were asked to walk as far as possible for 6 minutes in a flatcorridor which measures approximately 30 meters long. Baseline breathlessness was assessed using the mMRC scale (Table 1). Blood pressure, heart rate, respiratory rate, oxygen saturation and Borg dyspnea score (Table 2) were recorded at the beginning and at the 
Table 2. Borg dyspnea scale [16].

\begin{tabular}{cc}
\hline 0 & Nothing at all \\
0.5 & Very, very slight (just noticeable) \\
1 & Very slight \\
2 & Slight (light) \\
3 & Moderate \\
4 & Somewhat severe \\
5 & Severe (heavy) \\
6 & \\
7 & Very severe \\
8 & \\
9 & Very, very severe (maximal) \\
10 &
\end{tabular}

end of the 6 MWT. Distance covered is recorded and compared to a predicted value. BMI were divided into 3 obese classes: class1 $\left(30-34.9 \mathrm{~kg} / \mathrm{m}^{2}\right)$; class 2 (35 - $\left.39.9 \mathrm{~kg} / \mathrm{m}^{2}\right)$ and class $3\left(\geq 40 \mathrm{~kg} / \mathrm{m}^{2}\right)$. Airway obstruction is defined as FEV1/FVC ratio below the lower fifth percentile of healthy nonsmoking population. (LLN) [17] [18].

\section{Statistical Analysis}

Analysis of variance (ANOVA) model was used to evaluate the difference of key variables among three obesity classes. Fractional polynomial regressions were then used to explore the non-linear relationships between mMRC and Borg scores with BMI. Linear regression models were used to analyze the relationship of Borg scores and mMRC adjusted by age, lung capacities and airflow rates.

\section{Results}

\section{Demographic Characteristics}

Three hundred forty-two (342) patients with BMI $\geq 30 \mathrm{~kg} / \mathrm{m}^{2}$ have $6 \mathrm{MWT}$ form February 2008 till December 2014. Demographic profile of the study population is presented in Table 3. Their ages range from 28 to 92 years old with a mean age of 69 . More than half of the study group $(186,54.4 \%)$ belongs to obese class 1. There were 294 patients with spirometry. About $45.3 \%$ (133) of the patients have airflow obstruction (Table 3).

The study population was divided into 3 groups according to their BMI classes. Results of the $6 \mathrm{MWT}$ and PFT in each obesity subclass is presented in Table 4. Patients with the highest obesity class (BMI $\geq 40 \mathrm{~kg} / \mathrm{m}^{2}$ ) walked the least distance. The difference in the mean distance between those in the highest BMI class and the lowest BMI class is about 57 meters. As BMI increases there is a statistically significant decrease in FRC and increase of diffusion capacity ( $p \leq$ 
Table 3. Patient demographics.

\begin{tabular}{crc}
\hline \multicolumn{2}{c}{$\begin{array}{c}\text { Age }(\mathrm{n}=342) \\
\text { mean }\end{array}$} & $\begin{array}{c}(28-92) \\
(\mathrm{SD} 11.58)\end{array}$ \\
$30-34.9 \mathrm{~kg} / \mathrm{m}^{2}$ & BMI & \\
$35-39.9 \mathrm{~kg} / \mathrm{m}^{2}$ & Class 1 & $186(54.39 \%)$ \\
$\geq 40 \mathrm{~kg} / \mathrm{m}^{2}$ & Class 2 & $81(23.68 \%)$ \\
Full Spirometry $(\mathrm{n}=294)$ & $75(21.93 \%)$ \\
With Airway Obstruction & $133(45.29 \%)$ \\
No airway Obstruction & $161(54.76 \%)$ \\
\hline
\end{tabular}

BMI $=$ Body mass index

Table 4. Results of 6 Minute walk test (6 MWT) and Pulmonary Function Test (PFT) in each obesity subclasses.

\begin{tabular}{|c|c|c|c|c|}
\hline $6 \mathrm{MWT}$ and PFT parameters & $\begin{array}{c}\text { Class } 1 \\
30-34.9 \mathrm{~kg} / \mathrm{m}^{2}\end{array}$ & $\begin{array}{c}\text { Class } 2 \\
35-39.9 \mathrm{~kg} / \mathrm{m}^{2}\end{array}$ & $\begin{array}{c}\text { Class } 3 \\
\geq 40 \mathrm{~kg} / \mathrm{m}^{2}\end{array}$ & $P$ value \\
\hline $\begin{array}{l}\text { Distance walked-meters (mean) } \\
\qquad \mathrm{n}=342\end{array}$ & 313.53 & 300.86 & 256.73 & $<0.01$ \\
\hline $\begin{array}{l}\text { \% predicted distance on } 6 \mathrm{MWT} \\
\qquad \mathrm{n}=342\end{array}$ & 60.27 & 58.08 & 54.11 & 0.15 \\
\hline $\begin{array}{l}\text { Total lung capacity (TLC \%) } \\
\qquad \mathrm{n}=263\end{array}$ & 87.11 & 85.92 & 81.92 & 0.17 \\
\hline $\begin{array}{l}\text { Vital capacity (VC \%) } \\
\qquad \mathrm{n}=263\end{array}$ & 87.20 & 83.74 & 80.9 & 0.08 \\
\hline $\begin{array}{l}\text { Functional residual capacity (FRC\%) } \\
\qquad \mathrm{n}=263\end{array}$ & 89.38 & 87.15 & 75.62 & $<0.01$ \\
\hline $\begin{array}{l}\text { Residual volume (RV\%) } \\
\qquad \mathrm{n}=263\end{array}$ & 87.69 & 87.37 & 79.93 & 0.32 \\
\hline $\begin{array}{l}\text { Diffusion capacity (DLCO } \%) \\
\mathrm{n}=257\end{array}$ & 57.57 & 63.49 & 66.70 & $<0.01$ \\
\hline $\begin{array}{l}\text { Presence of airway obstruction } \\
\qquad \mathrm{n}=294\end{array}$ & 48.15 & 53.73 & 29.23 & 0.01 \\
\hline $\begin{array}{l}\text { MMRC dyspnea score (mean) } \\
\mathrm{n}=342\end{array}$ & 1.72 & 1.64 & 1.77 & 0.03 \\
\hline $\begin{array}{l}\text { Borg dyspnea score (mean) } \\
\qquad \mathrm{N}=342\end{array}$ & 3.31 & 3.33 & 3.41 & 0.12 \\
\hline
\end{tabular}

0.01 and $p \leq 0.01$ respectively; Table 4$)$. There is no statistically significant change in TLC, VC and RV with increasing weight ( $p=0.17, p=0.08$ and $p=$ 0.32 respectively). The likelihood of airflow obstruction decreases with increasing weight ( $p=0.01$; Table 4$)$.

Pre-exercise mMRC score is a strong predictor of higher post exercise dyspnea Borg scores in the obese population (coefficient $=0.764, p \leq 0.001$; Table 5). When adjusted to age, BMI, distance walked and FEV1 the relationship remained 
Table 5. Correlation of mMRC and Borg score in the non adjusted and adjusted group.

\begin{tabular}{ccc}
\hline Correlation of mMRC and Borg score & Correlation Coefficient & $P$ value \\
\hline Non adjusted $(\mathrm{n}=342)$ & 0.764 & $<0.001$ \\
$\begin{array}{c}\text { Adjusted with age, BMI, FEV1 and } \\
\text { \% predicted distance in 6 MWT }(\mathrm{n}=338)\end{array}$ & 0.670 & $<0.001$ \\
$\begin{array}{c}\text { Adjusted with age, BMI, FEV1, \% predicted distance, } \\
\text { TLC, FRC, DLCO, presence of AFO }(\mathrm{n}=254)\end{array}$ & 0.587 & $<0.001$ \\
\hline
\end{tabular}

statistically significant (coefficient $=0.670, P \leq 0.001$; Table 5 ). When lung volumes and the presence of airway obstruction were added in the adjustment, the relationship remained statistically significant. (coefficient $=0.586, p \leq 0.001$; Table 5). Higher weight was associated with higher mMRC and Borg score ( $p \leq$ 0.001 and $p=0.011$ respectively; Figure 1 ).

The study population was divided into 2 groups depending on the presence or absence of airflow obstruction. The relationship of mMRC scale and Borg dyspnea scores was even stronger in obese group with no airflow obstruction compared to the obstructed group (coefficient 0.880 in non-obstructed group vs. coefficient $=0.671$ in obstructed group; Table 6 ). When adjusted to age, BMI, FEV1, distance walked, TLC, FRC, DLCO, only the non-obstructed group showed statistically significant correlation (coefficient 0.677 $P=0.001$; Table 6).

\section{Discussion}

Obese population are at increased risk of exertional dyspnea even in the absence of an underlying respiratory illness. They are subjected to numerous tests to evaluate both cardiac and pulmonary etiology of symptoms. Oftentimes the mechanism of breathlessness remains unclear. Our study suggests a concise way to assess dyspnea in the obese population without subjecting patients to further exercise testing. The mMRC dyspnea scale, which is currently used as qualitative dyspnea scoring for patients with chronic respiratory disease (COPD and pulmonary fibrosis), has been validated for dyspnea assessment in the obese population in our study.

Three hundred forty-two (342) obese patients with 6 MWT had pre-exercise mMRC scores to assess their breathless of daily living. The reproducibility of 6 MWT in obese population makes it a good fitness indicator [11] [12]. Our study demonstrates a strong correlation between pre-exercise mMRC scores and post exercise Borg dyspnea scores after 6 MWT. When adjusted to BMI, age, distance walked and PFT parameters, a strong correlation still exists (Table 5).

The presence of mild restrictive defect and increased metabolic demand during exercise has been proposed etiologies for breathlessness in the obese population. The presence of adipose tissue in the chest wall and abdomen reduces FRC. This lung function changes is detectable even with modest increase in weight [2]. Similar restrictive pattern was seen in our study where patients on higher obesity class have significantly reduced FRC (Table 4). Reduction in FRC increases the 

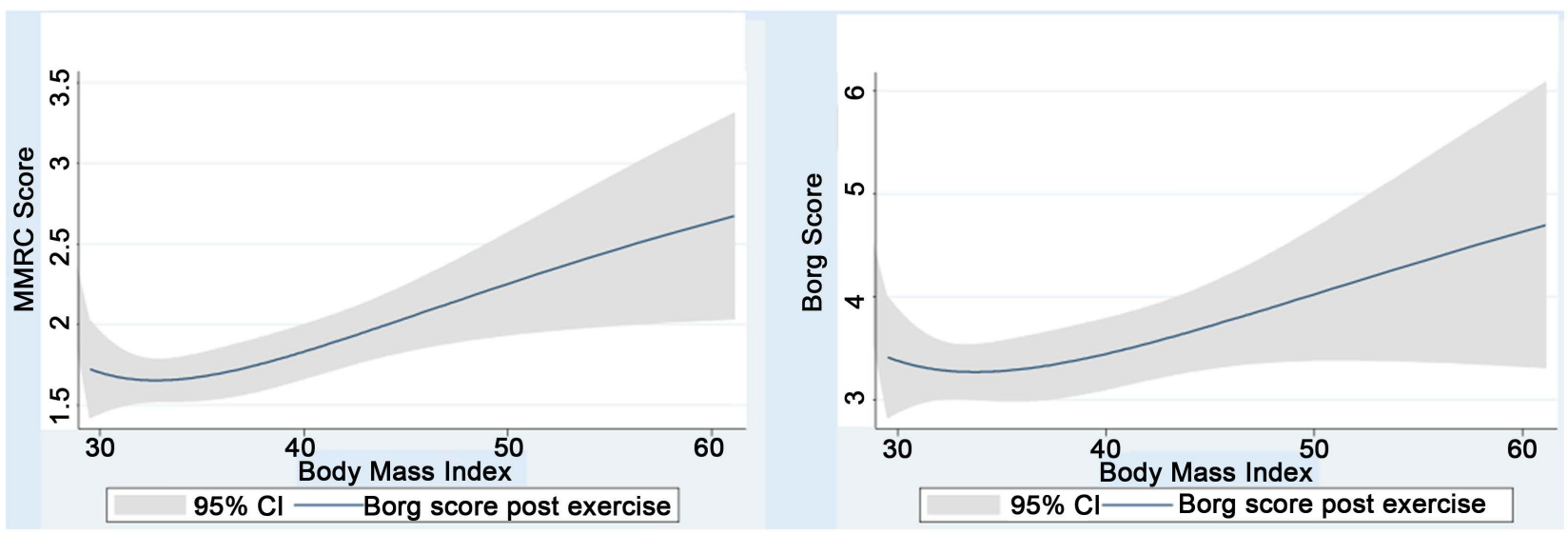

Figure 1. Individual correlation of mMRC and Borg score with BMI. Correlation of mMRC and BMI (adjusted $\mathrm{n}=254$, correlation coefficient 0.042, $p \leq 0.001$ ); Correlation of Borg score and BMI (adjusted $n=254$, correlation coefficient 0.062, $p=0.011$ ); Adjusted with age, FEV1, \% predicted distance, TLC, FRC, DLCO, presence of AFO.

Table 6. Correlation of mMRC and Borg score in relation with airflow obstruction (non adjusted and adjusted group).

\begin{tabular}{ccccc}
\hline \multirow{2}{*}{ Correlation of mMRC and Borg score } & \multicolumn{2}{c}{ With airflow obstruction } & \multicolumn{2}{c}{ No airflow obstruction } \\
\cline { 2 - 5 } & Coefficient & $P$ Value & Coefficient & $p$ Value \\
\hline Non adjusted & 0.6717 & $<0.001$ & 0.8804 & $<0.001$ \\
& $(\mathrm{n}=133)$ & & $(\mathrm{n}=161)$ & \\
Adjusted with age, BMI, FEV1 and & 0.5749 & 0.001 & 0.7476 & $<0.001$ \\
\% predicted distance & $(\mathrm{n}=133)$ & & $(\mathrm{n}=161)$ & \\
$\begin{array}{c}\text { Adjusted with age, BMI, FEV1 and \% } \\
\text { predicted distance, TLC, FRC, DLCO }\end{array}$ & $\begin{array}{c}0.4084 \\
(\mathrm{n}=114)\end{array}$ & 0.52 & $\begin{array}{c}0.6779 \\
(\mathrm{n}=140)\end{array}$ & 0.001 \\
\hline
\end{tabular}

risk of expiratory flow limitation and airway closure. In addition, low ERV may lead closure of airway in the dependent portion causing V/Q mismatch [2]. Sin et al. demonstrated that obese patients has increased use of bronchodilators despite a lack of objective evidence for airflow obstruction [3]. Ironically, obesity has little direct effect on the airway caliber and those with the highest BMI has the lowest risk for significant airflow obstruction. Similar findings were noted in this study where patients in obese class 3 have the lowest percentage of airflow obstruction (29\%, Table 4). The correlation of mMRC and Borg scores slightly differs when patients were divided into groups depending on the presence or absence of airflow obstruction. Our study demonstrated a stronger correlation of mMRC and Borg scores in obese patients without airflow obstruction. This finding illustrates the utility of mMRC scoring even in patients with no airway disease.

The strength of the study includes the assessment of the relationship of mMRC and Borg score after adjusting the major factors affecting dyspnea. These factors include pulmonary function test parameters, weight and age. The number of patients included in the study is relatively high. Our study also comes with its limitations. First, this is a retrospective observational study. Second, 6 MWT is not a standardize exercise stimulus. Cardiopulmonary exercise test would have 
provided us a global assessment of exercise response, determine functional capacity, work load, and impairment of ventilatory and cardiovascular response to exercise. Third, hip -waist ratio should have been considered.

\section{Conclusion}

The mMRC dyspnea scale is a qualitative parameter that reflects the disability associated with breathlessness. In obese population, pre-exercise dyspnea measured by mMRC scale correlates significantly with post exercise dyspnea Borg scores regardless of the presence or absence of airflow obstruction. We recommend the utility of mMRC dyspnea scale in assessing breathlessness in obesity. To our knowledge, this is the first validity study of mMRC scale in assessing dyspnea in the obese population.

\section{References}

[1] Ogden, C.L., Carroll, M.D., Kit, B.K. and Flegal, K.M. (2014) Prevalence of Childhood and Adult Obesity in the United States, 2011-2012. JAMA, 311, 806-814. https://doi.org/10.1001/jama.2014.732

[2] Salome, C.M., King, G.G. and Berend, N. (2010) Physiology of Obesity and Effects on Lung Function. Journal of Applied Physiology, 108, 206-211.

https://doi.org/10.1152/japplphysiol.00694.2009

[3] Sin, D.D., Jones, R.L. and Man, S.F.P. (2002) Obesity Is a Risk Factor for Dyspnea but Not for Airflow Obstruction. Archives of Internal Medicine, 162, 1477. https://doi.org/10.1001/archinte.162.13.1477

[4] Collet, F., Mallart, A., Bervar, J.F., Bautin, N., Matran, R., Pattou, F., et al. (2007) Physiologic Correlates of Dyspnea in Patients with Morbid Obesity. International Journal of Obesity (London), 31, 700-706. https://doi.org/10.1038/sj.ijo.0803460

[5] O’Donnell, D.E., O’Donnell, C.D.J., Webb, K.A. and Guenette, J.A. (2012) Respiratory Consequences of Mild-to-Moderate Obesity: Impact on Exercise Performance in Health and in Chronic Obstructive Pulmonary Disease. Pulmonary Medicine, 2012, Artilce ID: 818925. https://doi.org/10.1155/2012/818925

[6] Zutler, M., Singer, J.P., Omachi, T.A., Eisner, M., Iribarren, C., Katz, P., et al. (2012) Relationship of Obesity with Respiratory Symptoms and Decreased Functional Capacity in Adults without Established COPD. Primary Care Respiratory Journal, 21, 194-201. https://doi.org/10.4104/pcrj.2012.00028

[7] Lin, C.-K. and Lin, C.-C. (2012) Work of Breathing and Respiratory Drive in Obesity. Respirology, 17, 402-411. https://doi.org/10.1111/j.1440-1843.2011.02124.x

[8] Mahler, D.A. and Wells C.K. (1988) Evaluation of Clinical Methods for Rating Dyspnea. Chest, 93, 580-586. https://doi.org/10.1378/chest.93.3.580

[9] Launois, C., Barbe, C., Bertin, E., Nardi, J., Perotin, J.-M., Dury, S., et al. (2012) The Modified Medical Research Council Scale for the Assessment of Dyspnea in Daily Living in Obesity: A Pilot Study. BMC Pulmonary Medicine, 12, 61. https://doi.org/10.1186/1471-2466-12-61

[10] Stenton, C. (2008) The MRC Breathlessness Scale. Occupational Medicine (London), 58, 226-227. https://doi.org/10.1093/occmed/kqm162

[11] Beriault, K., Carpentier, A.C., Gagnon, C., Ménard, J., Baillargeon, J.-P., Ardilouze, J.-L., et al. (2009) Reproducibility of the 6-Minute Walk Test in Obese Adults. International Journal of Sports Medicine, 30, 725-727. 
https://doi.org/10.1055/s-0029-1231043

[12] Larsson, U.E. and Reynisdottir, S. (2008) The Six-Minute Walk Test in Outpatients with Obesity: Reproducibility and Known Group Validity. Physiotherapy Research International, 13, 84-93. https://doi.org/10.1002/pri.398

[13] Hsu, K.-Y., Lin, J.-R., Lin, M.-S., Chen, W., Chen, Y.-J. and Yan, Y.-H. (2013) The Modified Medical Research Council Dyspnoea Scale Is a Good Indicator of Health-Related Quality of Life in Patients with Chronic Obstructive Pulmonary Disease. Singapore Medical Journal, 54, 321-327. https://doi.org/10.11622/smedj.2013125

[14] Hajiro, T., Nishimura, K., Tsukino, M., Ikeda, A., Koyama, H. and Izumi, T. (1998) Analysis of Clinical Methods Used to Evaluate Dyspnea in Patients with Chronic Obstructive Pulmonary Disease. American Journal of Respiratory and Critical Care Medicine, 158, 1185-1189. https://doi.org/10.1164/ajrccm.158.4.9802091

[15] ATS (2002) Statement: Guidelines for the Six-Minute Walk Test. American Journal of Respiratory and Critical Care Medicine, 166, 111-117. https://doi.org/10.1164/ajrccm.166.1.at1102

[16] Mahler, D.A. and Horowitz, M.B. (1994) Perception of Breathlessness during Exercise in Patients with Respiratory Disease. Medicine and Science in Sports and Exercise, 26, 1078-1081. https://doi.org/10.1249/00005768-199409000-00002

[17] Miller, M.R., Quanjer, P.H., Swanney, M.P., Ruppel, G. and Enright, P.L. (2011) Interpreting Lung Function Data using 80\% Predicted and Fixed Thresholds Misclassifies More than 20\% of Patients. Chest, 139, 52-59.

https://doi.org/10.1378/chest.10-0189

[18] Pellegrino, R., Viegi, G., Brusasco, V., Crapo, R.O., Burgos, F., Casaburi, R., et al. (2005) Interpretative Strategies for Lung Function Tests. The European Respiratory Journal, 26, 948-968. https://doi.org/10.1183/09031936.05.00035205 